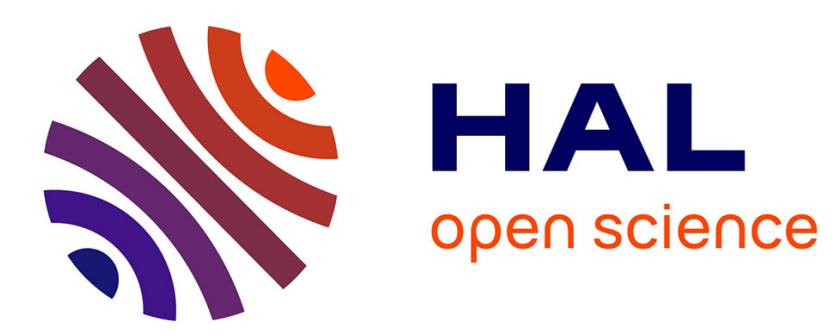

\title{
Bubble Formation Dynamics in Various Flow-Focusing Microdevices
}

\author{
N. Dietrich, S. Poncin, N. Midoux, H.-Z. Li
}

\section{To cite this version:}

N. Dietrich, S. Poncin, N. Midoux, H.-Z. Li. Bubble Formation Dynamics in Various Flow-Focusing Microdevices. Langmuir, 2008, 24 (24), pp.13904-13911. hal-00379309

\section{HAL Id: hal-00379309 \\ https://hal.science/hal-00379309}

Submitted on 23 Jul 2021

HAL is a multi-disciplinary open access archive for the deposit and dissemination of scientific research documents, whether they are published or not. The documents may come from teaching and research institutions in France or abroad, or from public or private research centers.
L'archive ouverte pluridisciplinaire HAL, est destinée au dépôt et à la diffusion de documents scientifiques de niveau recherche, publiés ou non, émanant des établissements d'enseignement et de recherche français ou étrangers, des laboratoires publics ou privés. 


\title{
BUBBLE FORMATION DYNAMICS IN VARIOUS FLOW-FOCUSING MICRO-DEVICES
}

\author{
N. Dietrich, S. Poncin, N. Midoux and Huai Z. LI* \\ Laboratoire des Sciences du Génie Chimique, Nancy-Université, CNRS \\ 1 rue Grandville, BP 20451, 54000 Nancy Cedex, France
}

* To whom correspondence should be addressed.

Tel.: +33(0)3 831751 09, Fax: +33 (0)3 8332 29 75, E-mail: Huai-Zhi.Li@ensic.inpl-nancy.fr

Keywords: bubble formation, micro-mixer, flow focusing, $\mu$ PIV, correlation

\begin{abstract}
The aim of this study is to investigate three types of gas-liquid micro-mixer geometries, including a cross-shape and two converging shape channels for the bubble formation in different liquids. The bubble shape, size and formation mechanism were investigated under various experimental conditions such as flowrates of two phases, physical properties of liquid and mixer's geometries. A micro-Particle Image Velocimetry ( $\mu$-PIV) technique and a high speed camera were used to characterize and quantify gas-liquid flows. It was revealed that the bubble formation, in particular the bubble size, depends on the geometry of the mixing section between two phases. A correlation gathering numerous experimental data was elaborated for the estimation of bubble size. The influence of different parameters like flowrate ratio between two phases, surface tension and liquid's viscosity is well taken into consideration based on the understanding of bubble formation mechanism at microscale. This paper marks an original improvement in the domain where no flow field characterisations or correlations were established in flow focusing devices.
\end{abstract}




\section{Introduction}

Multiphase flows in microfluidic devices have recently received much attention because of the foreseeable advantages that unique microscale properties have to offer such as enhancement of heat and mass transfer efficiency reduced axial dispersion and smaller sample volumes. In order to quantify these benefits, a good understanding of the complex multiphase flow behavior in microfluidic devices must be gained. In particular, the formation of bubbles finds very wide applications such as the generation of biogas bubbles by anaerobic sludge granules in a bioreactor ( $\mathrm{Wu}$ et al., 2006), bubble nucleation in polymer devolatization processes (Frank et al., 2007), two-phase micro-mixing (Garstecki et al., 2006), fluorinations (Chambers et al., 2001), hydrogenations (Kobayashi et al., 2004), biochemical reactions such as DNA analysis (Burns et al., 1998), micro-channel heat exchangers (Qu \& Mudawar, 2002), materials synthesis (Yen et al., 2005; Zhang et al., 2006), drug discovery (Dittrich \& Manz, 2006).

The two-phase flow patterns in microchannels are determined by the flow conditions, the channel geometry and the properties of both fluids involved. Generally, the gas-liquid flow in microchannels can be classified into five different regimes, namely, the bubbly flow, the slug flow, the slug annular flow, the annular flow and the spray flow (Waelchli \& Rohr, 2006). The bubbly flow is characterized by the formation of single spherical bubbles with bubble lengths smaller than, or equal to the channel width. Increasing the gas flowrate causes the coalescence of small bubbles leading to cylindrical bubbles (separated from the wall by a very thin film), this regime is known as slug flow and also as plug, bubble-train, or Taylor bubble. Thereafter, slug-annular flow develops, in which waves are formed from the annular film that are not large enough to fill the entire channel diameter. A supplementary increase in the gas flowrate leads to the annular flow regime, characterized by the presence of a substantial liquid 
film at the wall and a central gas stream. When the gas flowrate is further increased, the spray flow takes place, which consists of very small droplets of liquid in a continuous gas phase. This flow regime map has been developed by several authors (Cubaud \& Ho, 2004, Haverkamp et al., 2006), usually as a function of the superficial velocities of the gas and liquid phases. Finally, bubbly flow appears at high liquid flowrates and low gas velocities and slug flow occurs at intermediate gas and liquid velocities. In the present study, experiments are mainly focused on the segmented gas-liquid flows, i.e., bubbly and slug regimes.

The most popular geometries for the generation of dispersed phases are $T$-junctions (Garstecki et al., 2006; van der Graaf et al., 2006; Guillot and Colin, 2005; Nisisako et al., 2002; Thorsen et al., 2001; Tice et al., 2003; Xu et al., 2006) and flow-focusing devices (Anna et al., 2003; Cubaud et al., 2005; Ganan-Calvo and Gordillo, 2001; Garstecki et al., 2005). Garstecki et al. (2005) used a flow-focusing device of small orifice to generate monodispersed bubbles. They found that the bubble formation was governed by the pressure gradient and the breakup could be controlled by the flowrate of the continuous liquid phase. Cubaud \& Ho (2004) studied the formation of bubbles in square micro-channels through a cross-shaped mixing section. They reported that the breakup mechanism in their devices could be attributed to a competition between the pressures in gas and liquid phases.

Recently, liquid flow fields in microfluidic devices have been investigated by means of micro-Particle Image Velocimetry ( $\mu$-PIV) technique. For example, single-phase flows in microfluidic $T$-junctions were characterized by $\mu$-PIV technique (Lindken et al., 2006). Earlier, Thulasidas et al. (1997) used a classical PIV to measure the liquid velocity distribution in a segmented gas-liquid flow within capillaries of round and square cross section. Xiong et al. (2007) described the formation of bubbles in a simple co-flowing micro- 
channel. Their $\mu$-PIV measurements show that the bubble formation is due to the velocity component perpendicular to the gas flow created by the sudden change of the liquid velocity distribution around the channel frontier. Fries et al. (2008) studied the two counter rotating vortices created in slug flow between two gas bubbles. $\mu$-PIV measurements reveal that the recirculation movement in microchannels is very sensitive to the channel geometry. They present the influence of the superficial velocities, channel diameter and curve radius on the recirculation motion and demonstrate that for segmented gas-liquid flow, an increase of mass transfer over the complete channel diameter is possible by using meandering channels. It is worth noting that up to now, there are still very few $\mu$-PIV studies devoted to the flow fields around a bubble in formation. Velocity fields obtained by $\mu$-PIV have been reported for the bubble formation in a $T$-junction (Van Steijn et al., 2007) and in a $Y$-junction (Dietrich et al., 2007). There is no reported work in micro flow-focusing devices to our best knowledge.

For many industrial applications, it is essential to be able to establish the relationship between the geometric features and the flow pattern such as bubble and slug length. Some correlations were proposed to characterise the formation of bubbles (length or volume). Ganan-Calvo (1998) proposed a correlation for jet flow; Ganan-Calvo and Gordillo (2001) studied a cross flow-focusing mixer and proposed a correlation between the bubble length and flowrate ratios without precision about the physical properties of liquid. Cubaud et al. (2005) showed that the length of the confined bubbles follows a law based on the channel size and the liquid volume fraction. Garstecki et al. (2006) studied a cross flow micro-mixer and also developed a simple correlation between the flowrate ratio and bubble length. To our best knowledge, no correlation exists for the estimation bubble volume including wide physical properties of liquid. 
In the literature, the effect of the micro-mixer geometry was still few studied. Haverkamp et al. (2006) studied the flow of gas-water in two mixing geometries: "T-type" and "smooth" mixers. They reported that the breakup by pressure gradient was only observed in the T-type mixer, while the jet instability was the unique mechanism for bubble formation in the smooth mixer. Fan et al. (2007) investigated two types of mixer geometries including the cross and converging shape channels. The bubble shape and size and the formation mechanism were considered for different flowrates. Theses authors compared satisfactorily the simulated results with experimental data in the form of dimensionless numbers. Different flow regimes with different bubble shapes were found depending on the capillary number of the flow. The simulated data confirmed that the breakup was induced by the pressure difference in both phases. The geometry of the mixing section was also observed to have an impact on the size of the gas and liquid slugs, but no experimental quantification of bubble size and velocity flow field was realised.

The present work is devoted to the formation of bubbles in flow-focusing micro-mixer s of different geometries. By means of a $\mu$-PIV system and a high speed digital camera, the role of inertial, viscous and interfacial forces was experimentally investigated to gain new insight into the mechanism of bubble formation at microscale.

\section{Experimental setup}

The different geometries of micro-mixer s used in this study are shown in Figure 1. The microchannels were fabricated in polymethyl methacrylate (PMMA). This flow-focusing geometry has a central channel for the dispersed gas phase flow, and two side channels for the inlet of the continuous liquid phase. Two different sizes of liquid inlet and outlet channels (600 $\mu \mathrm{m}$ and $1000 \mu \mathrm{m})$, and of gas inlet channels $(200 \mu \mathrm{m}$ and $500 \mu \mathrm{m})$ were used. The 
section of the gas inlet is circular in order to avoid wetting problems, and the other sections are square to enable a better visualisation of the flow field.
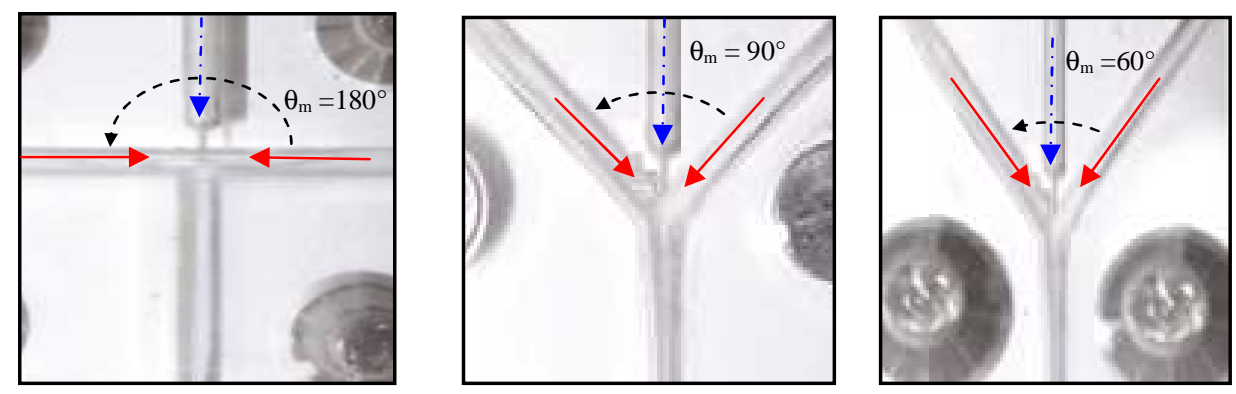

Gas flow

Liquid flow

Figure 1. Illustration of the micro fluidic chip used to generate micro-bubble. From the left to the right, cross shape $\left(180^{\circ}\right)$, Convergence shape $\left(90^{\circ}\right.$ and $\left.60^{\circ}\right)$.

Two pressurized tanks of $10^{-3} \mathrm{~m}^{3}$ were used to maintain a constant pressure and to push the liquid and air streams into the microchannel with a regular flowrate of each phase. A gas flow-meter was used to determine the flowrate with precision. Images of bubbles were captured by a high speed digital camera CamRecord600 (Optronis GMBH, Germany) equipped with a microscopic objective ranging from $\times 100$ to $\times 600$. The typical acquisition rate was 500 frames per second with a full resolution $(1280 \times 1024)$. Under the steady formation conditions, the length of the bubble was determined through an image analysis software and the bubble volume $V_{b}$ was calculated from the gas flowrate $Q_{g}$ and the bubble formation frequency $f$ determined by the high speed camera as follows:

$$
V_{b}=\frac{Q_{g}}{f}
$$

The Instantaneous liquid velocity flow fields were measured by a $\mu$-PIV system (Dantec Dynamics, Denmark). The system consists of a Flowsense Dantec Camera with a 2048×2048 pixel array and a $7 \mathrm{~Hz}$ frequency. The inversed microscope Leica was equipped with different objectives ranging from $\times 5$ to $\times 100$. The micro-device under investigation faced the 
microscope and was illuminated from the back by a micro-strobe emitting a light at $530 \times 10^{-9}$ m.
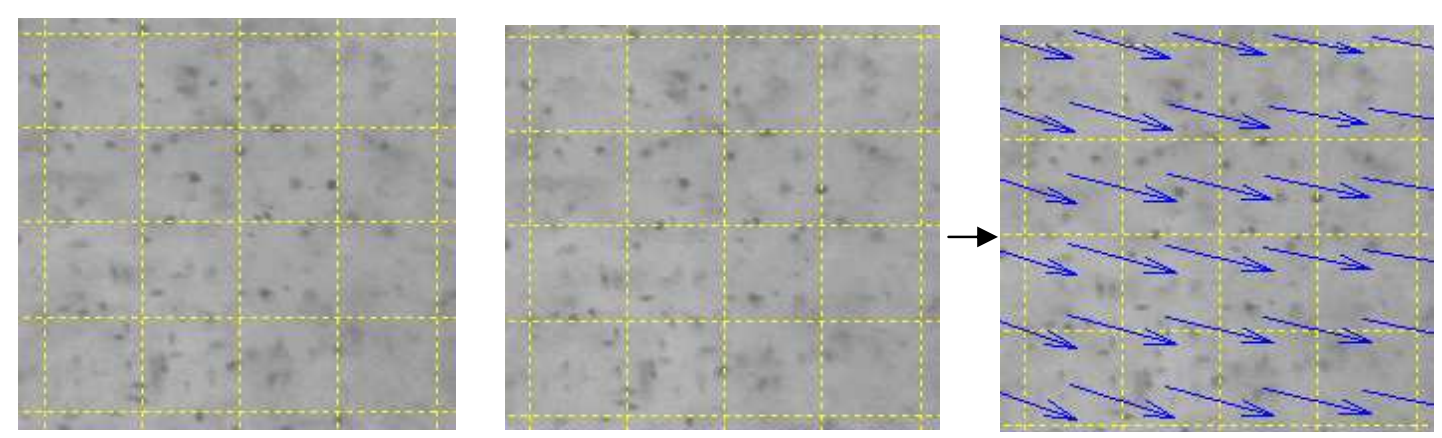

Figure 2. Micro Particle Image Velocimetry principle ( $\mu$-PIV). $50 \times 50 \mu \mathrm{m}$ windows.

The liquid velocity fields were measured by tracking and evaluating the motion of seeding particles suspended in the fluid. The principle of $\mu$-PIV is reported in Figure 2. The camera took two successive images at the maximum intensity of the micro stroboscope impulse. The acquired images of the flow were analysed by dividing the images into a few thousands of small interrogation areas of $16 \times 16$ pixels. A cross-correlation was then applied on the interrogation areas in consecutive images with a 50\% window overlap. For each interrogation area, the displacement vector was calculated from the location of the correlation peak. The velocity fields were then calculated from the displacement vectors and the time chosen between the images. The measurements were realized on a slice of the micro-mixer of a value around $10 \mu \mathrm{m}$ due to the focus of the microscope. However, this value is negligible in comparison with the thickness of the microchannel. Seeding particles should be uniformly dispersed in fluid with a reasonable concentration. The density should be similar to that of studied fluid. If the seeding particles used are too small, the Brownian motion could induce errors in measurements. This random motion sets a lowest limit of seeding particles' size to achieve $\mu$-PIV measurements. Starting from the equation of Einstein-Sutherland (1905), it is possible to estimate the influence of this Brownian motion through a diffusion coefficients $D$ : 


$$
D=\frac{k T}{6 \pi \mu r}
$$

$\mathrm{T}$ is the temperature, $\mu$ fluid viscosity, $r$ the particle radius and $k$ the Boltzmann constant. This equation shows that the Brownian motion depends inversely on the radius of the particle. The standard deviation of the random movement of a particle is given by as follows:

$$
\Sigma_{p}=\Delta x_{p} \approx \sqrt{2 D \delta t}
$$

Thus, for a camera frequency of $4 \mathrm{~s}^{-1}$ and a particle diameter of $200 \times 10^{-9} \mathrm{~m}$, the random movement is estimated at $3 \times 10^{-6} \mathrm{~m} \cdot \mathrm{s}^{-1}$. The liquid velocity used in this study being several hundreds micrometers per second, an error of order of percent is then expected for the velocity. Larger particles should be chosen to avoid inaccuracy problems due to the Brownian motion. But bigger the particle is, higher is its settling velocity. The sedimentation velocity of a particle of diameter $d$ is estimated in the Stokes' regime

$$
v_{p}=\frac{d^{2} g\left(\rho_{p}-\rho_{l}\right)}{18 \mu}
$$

For seeding particles of $3 \times 10^{-6} \mathrm{~m}$ diameter, the value of the sedimentation velocity is around $1.5 \times 10^{-6} \mathrm{~m} . \mathrm{s}^{-1}$. Finally, to reach a suitable compromise between the Brownian motion and settling velocity for which the relative error is below $1 \%$, the optimal size of seeding particle has to be in the range $\left[0.5-3 \times 10^{-6} \mathrm{~m}\right]$. Furthermore, the size of the geometry, viewing windows and camera objectives help to refine the value of the particle diameter. In this study, hydrophilic latex microspheres (Merck Estapor, France) with a density of $1056 \mathrm{~kg} \cdot \mathrm{m}^{-3}$ and a mean calibrated diameter of $0.88 \times 10^{-6} \mathrm{~m}$ were used as seeding particles. These particles were small enough to follow the fluid and large enough to avoid the Brownian motion effects. When the flow is correctly inseminated, the measurement errors of the measured velocities are less than $5 \%$. 
In this work, the experiments were performed using air as gas phase and three different liquids (pure water, viscous Newtonian Emkarox HV45 10\% and 20\% wt dilute solutions in demineralised water). A Rheometric Fluid Spectrometer RFS II (Rheometric Scientific) was employed to characterize the rheological properties of the liquids (Table 1). The surface tension and the contact angle of the liquid on the PMMA surface were measured using a tensiometer, by the pending drop technique on a Tracker apparatus (I.T. Concept, France).

Sodium Dodecyl Sulphate surfactant (SDS, Amersco, USA) was also used to modify the surface tension, which allows to compare separately the effect of surface tension and viscous force. Table 1 gathers all properties of the various liquids used. All experiments were carried out at a constant temperature of $293 \mathrm{~K}$.

Table 1. Properties of the different liquids used in this study at $293 \mathrm{~K}$.

\begin{tabular}{l|c|c|c|c}
\hline \multicolumn{1}{c|}{ Fluid } & $\rho\left({\left.\mathrm{kg} . \mathrm{m}^{-3}\right)}^{-}\right.$ & $\mu\left(\times 10^{3}\right.$ Pa.s $)$ & $\theta_{\text {contact }}$ & $\sigma\left(\times 10^{3}{\mathrm{~N} . \mathrm{m}^{-1}}^{-1}\right.$ \\
\hline Water & 1000 & 1 & $66^{\circ}$ & 72 \\
Water + 0.10\% SDS (wt) & 1000 & 1 & $64^{\circ}$ & 50 \\
Water + 0.15\% SDS (wt) & 1000 & 1 & $62^{\circ}$ & 40 \\
\hline HV45 10\% (wt) & 1030 & 10 & $53^{\circ}$ & 50 \\
HV45 10\% (wt) + 0.05\% SDS (wt) & 1030 & 10 & $56^{\circ}$ & 40 \\
\hline HV45 25\% (wt) & 1050 & 30 & $46^{\circ}$ & 40
\end{tabular}

\section{Experimental results}

In the present work, extensive experimental investigation was realized for the bubble formation in three different micro-mixer geometries of various junction angles $(180,90$ and $60^{\circ}$ ). In order to understand the key parameter of the bubble formation process, a preliminary study was devoted to the influence of each factor. The gas and liquid flowrates range from $10^{-}$ ${ }^{12} \mathrm{~m}^{3} \cdot \mathrm{s}^{-1}$ to $10^{-6} \mathrm{~m}^{3} \cdot \mathrm{s}^{-1}$, which correspond to the bubbly and slug flow regimes and bubble diameters between $50 \times 10^{-6} \mathrm{~m}$ and $5 \times 10^{-3} \mathrm{~m}$. The bubble formation was studied by both $\mu-$ PIV and high speed camera visualization. The shape evolution of a $10^{-9} \mathrm{~m}^{3}$ bubble in time 
during the formation process until to its detachment is shown in Fig. 3. The bubble formation was perfectly periodic with a frequency of $34 \mathrm{~s}^{-1}$. Figure 3 shows the growth process during one period. The bubble shape was obtained thanks to a high speed camera. One can distinguish three steps during the formation of the bubble: firstly a rapid expansion step of the growing bubble; secondly, a steady increase of the bubble and the last step corresponding to a fast elongation of the bubble which is stretched and elongated due to the orifice geometry as well as the lateral flow leading to its rupture.

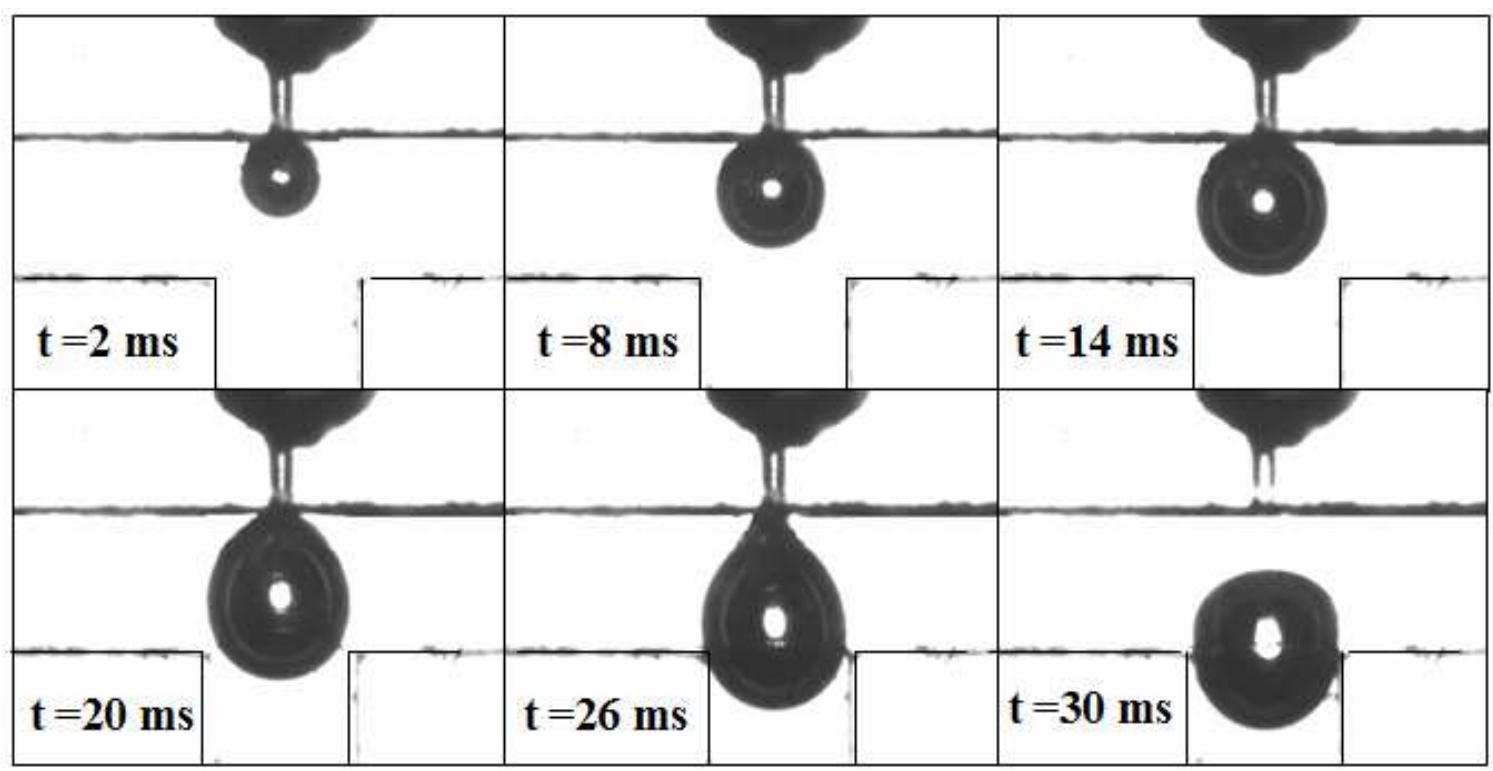

Figure 3. Bubble formation in cross flow-focusing micro-mixer. $\mathrm{V}_{\mathrm{b}}=10^{-9} \mathrm{~m}^{3}$. Gas inlet channel is $200 \mu \mathrm{m}$, liquid inlet and outlet channels are $1000 \mu \mathrm{m}$, the liquid is pure water, liquid and gas flowrate are $10^{-8} \mathrm{~m}^{3} \cdot \mathrm{s}^{-1}$

It is clearly seen that in this case, a bubble expands spherically at the beginning of the bubble formation, then evolves from spherical shape to axisymmetrical teardrop shape. In this stage the bubble grows without significant movement into the stream direction and the liquid circulates easily around the growing bubble. Subsequently, the effect of flow inertia on the bubble becomes gradually important during the growth of the bubble, the interface 
moves and the bubble is stretched to form a neck that is elongated to an obvious teardrop shape until to the rupture. Fig. 4 represents the velocity fields of liquid around a bubble in a cross shape flow-focusing micro-mixer. At $\mathrm{t} / \mathrm{t}_{\mathrm{f}}=0.05$ (Fig. 4a), the bubble starts its progression in the main central zone and does not seem to perturb much the flow. At $t / t_{\mathrm{f}}=$ 0.3 (Fig. 4b), the flowrate of the continuous liquid is bypassing the bubble as an obstacle.
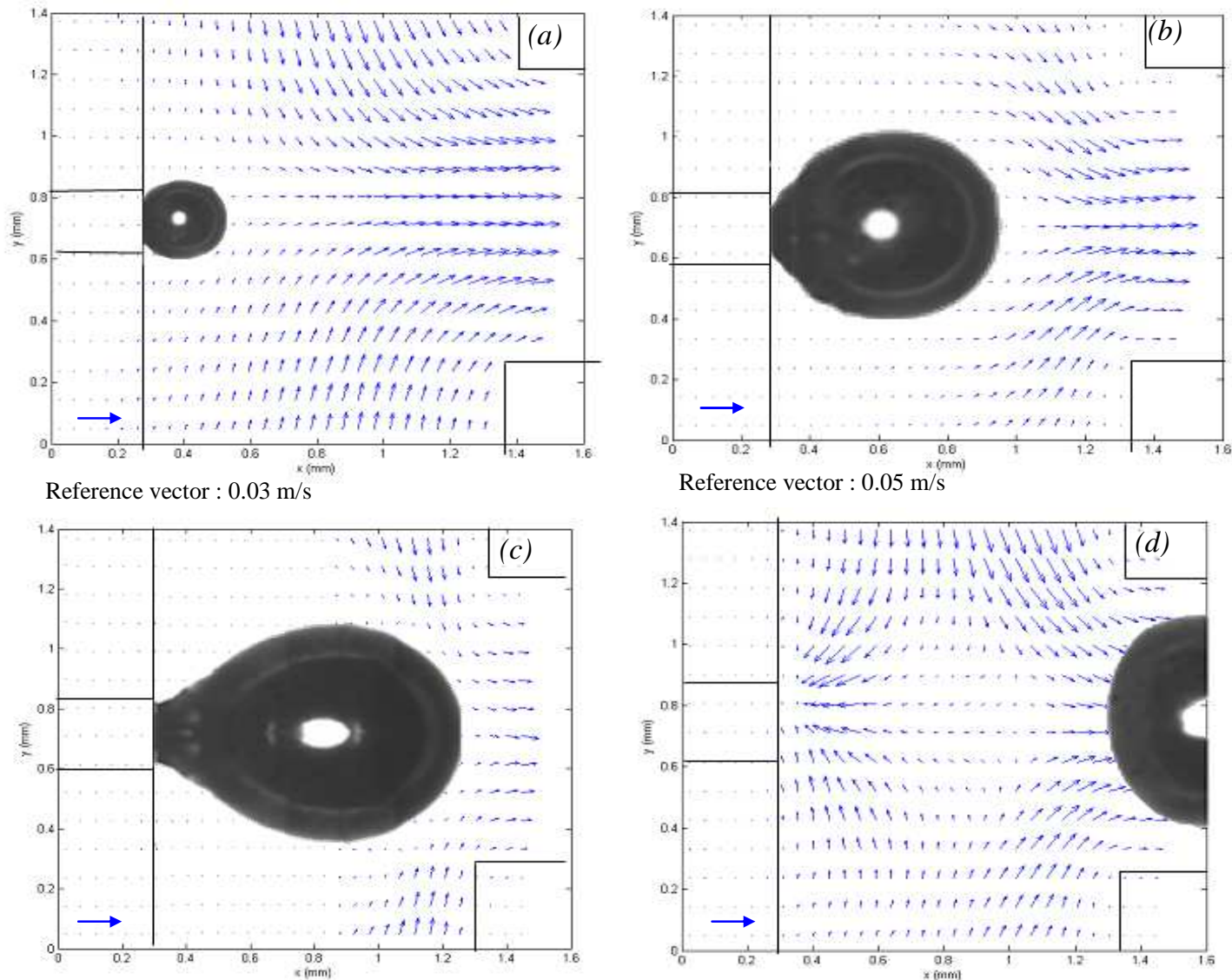

Reference vector : $0.1 \mathrm{~m} / \mathrm{s}$

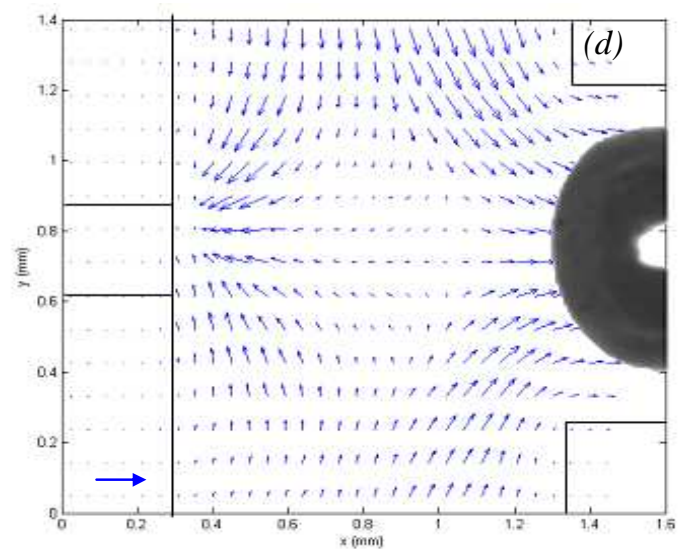

Reference vector : $0.04 \mathrm{~m} / \mathrm{s}$

Figure 4. Velocity field measurement by $\mu$-PIV system for a $10^{-9} \mathrm{~m}^{3}$ bubble formation in a cross flow-focusing mixer. The focus plane of the $\mu$-PIV measurement is situated in the middle of the channel. Gas inlet phase is $200 \mu \mathrm{m}$, liquid inlet and outlet channels are 1000 $\mu \mathrm{m}$, the liquid is pure water (a) $\mathrm{t} / \mathrm{t}_{\mathrm{f}}=0.05 ;$ (b) $\mathrm{t} / \mathrm{t}_{\mathrm{f}}=0.3$ (c) $; \mathrm{t} / \mathrm{t}_{\mathrm{f}}=0.8 ;$ (d) $\mathrm{t} / \mathrm{t}_{\mathrm{f}}=1$. 
When the bubble fills up the cross-junction, the liquid flow pattern in the two lateral channels becomes reduced and confined to the wall of the channels. At $\mathrm{t} / \mathrm{t}_{\mathrm{f}}=0.8$ (Fig. $4 \mathrm{c}$ ), the velocity fields vanishes almost in the channel. Close to the gas-liquid interface the liquid flow is accelerate due to the mass conservation. As a result, relatively high velocities up to four times the average velocity are obtained in the gap between the gas-liquid interface and the opposite wall of channel. At $t / t_{\mathrm{f}}=1$ (Fig. 4d), the formation cycle ends with the break-up of the neck of the bubble and the formed bubble enters in the main channel. The velocity flow field is directed into both opposite directions due to the release of the surface energy when the bubble snaps.

The $\mu$-PIV technique is a powerful tool to evaluate the main forces acting on the bubble. As shown in Figs. 4c and 4d, the neck interface undergoes the deformation under shear stresses which can be estimated from the liquid flow gradient at the interface of the bubble. For example, in Figs. 3 and 4, the shear rate is about $500 \mathrm{~s}^{-1}$. By comparison with other forces acting on the bubble, the shear stress is not the key force. Table 2 presents the typical values of three main forces which act on the bubble during the formation and break-up. The main formation mechanism depends on the competition between theses forces: the static pressure and surface tension play a major role with respect to the shear stress. The measurement of the flow field around a forming bubble in a flow-focusing microfluidic system comforts the proposed formation mechanism in the literature results (Cubaud et al., 2005; Garstescki et al., 2006). 
Table 2. Three main forces acting on a forming bubble in a flow-focusing micro-mixer for a bubble radius at detachment of $300 \times 10^{-6} \mathrm{~m}$.

\begin{tabular}{c|c|c}
\multicolumn{2}{c|}{ Three main forces acting on the bubble } & Values for Figs. 3\& 4 \\
\hline Shear stress & $\tau=\mu \dot{\gamma}$ & $\tau=0.5 \mathrm{~Pa}$ \\
\hline Surface tension & $\Delta P_{\sigma}=\frac{2 \sigma}{R}$ & $\Delta \quad \underline{\sigma}_{4} 483$ \\
\hline Pressure distribution & $\Delta P=\frac{1}{2} \rho v^{2}$ & $\Delta P=1.25 \mathrm{~Pa}$
\end{tabular}

Moreover, as shown in Figures 3 and 4, the bubble shape is not so deformed. This can be explained by the dominant value of the surface tension evaluated according to the Laplace's equation with respect to other two forces. This results also in a very small deformation of the bubble during its formation. Besides the measurement of local flow properties by means of $\mu$ PIV, the global properties such as bubble length and volume were quantified using a high speed digital camera and a flowmeter. It is therefore possible to determine the physical key factors involved in the formation mechanism.

The flowrate ratio seems to play an important role in the formation of micro-bubbles. Figure 5a illustrates the evolution of the dimensionless ratio L/W of the bubble length to the channel width with the gas flowrate (when liquid flow is constant) and inversely. 

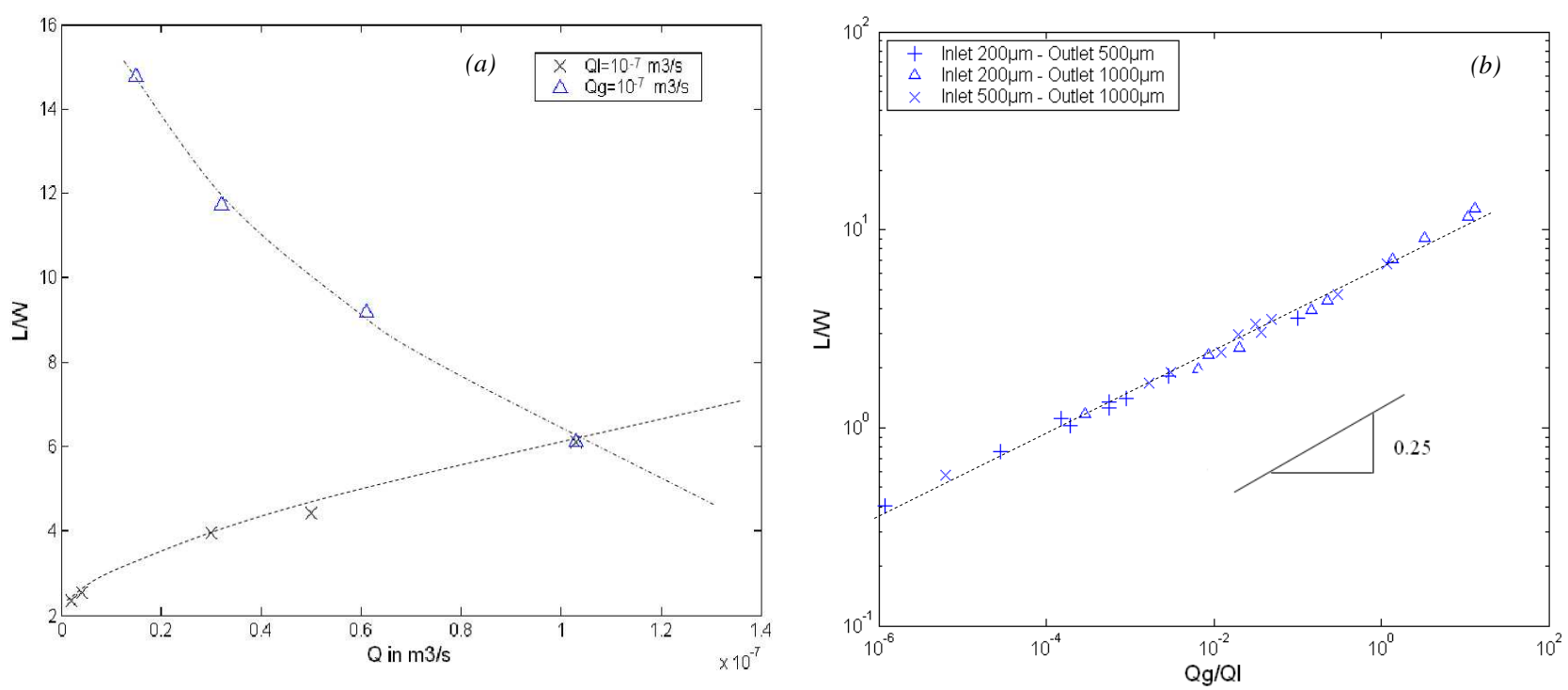

Figure 5. (a) Influence of gas and liquid flowrate on the bubble length to channel width ratio $(\mathrm{L} / \mathrm{W}) .(\times) v s . \mathrm{Q}_{\mathrm{g}}$ at constant $\mathrm{Q}_{1}(\triangle)$ vs. $\mathrm{Q}_{1}$ at constant $\mathrm{Q}_{\mathrm{g}}$.Inlet channel size $200 \mu \mathrm{m}$ and outlet channel size $1000 \mu \mathrm{m}$.(b) Effect of inlet and outlet channel sizes on the evolution of L/W as function of the flowrates ratios in water.

These results show that the detached bubble length is affected by both gas and liquid flowrates. The bubble volume increases gradually with the gas flowrate, and decreases with the liquid flowrate. This slow evolution may be explained by the increase of shear stress and elongation when the liquid flowrate increases leading to the formation of smaller bubbles.

The evolution of $\mathrm{L} / \mathrm{W}$ ratio as a function of the $\mathrm{Q}_{\mathrm{gas}} / \mathrm{Q}_{\text {liquid }}$ ratio for various sizes of the gas inlet and gas-liquid outlet (Figure 5b) may be represented by the following correlation:

$$
\frac{L}{W}=\beta\left(\frac{Q_{\text {gas }}}{Q_{\text {liquid }}}\right)^{\alpha}
$$

where both the power law index $\alpha=0.25$ and constant $\beta$ value depend on the liquid physical properties and the geometry of the micro-mixers. This simple correlation describes quite well 
the influence of both flowrate and also the size of the micro-mixers' channels. In the study of Ganan and Gordillo (2001), the similar results were found with a power law index of 0.37 . The difference could stem from a bigger size of their inlet channel . In order to improve this correlation, the liquid physical properties such as the surface tension $\sigma$, the viscosity $\mu$ and also the geometry of the mixer are varied to investigate their respective influence. Figure 6 shows the evolution of $\mathrm{L} / \mathrm{W}$ ratio as a function of the $\mathrm{Q}_{\mathrm{g}} / \mathrm{Q}_{\mathrm{l}}$ flowrate ratio.
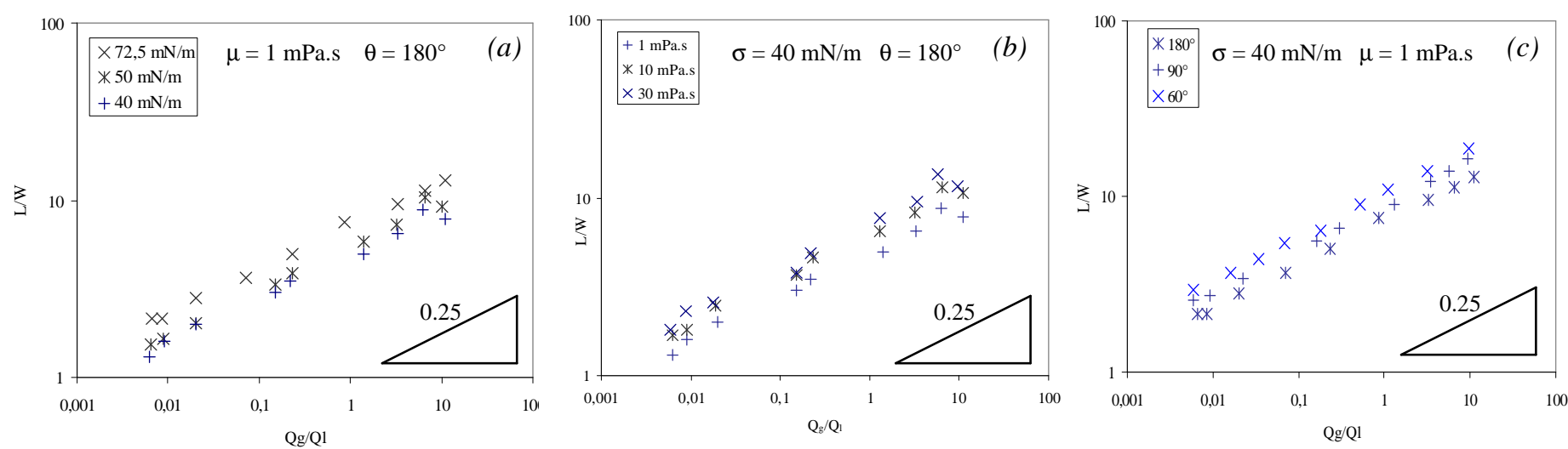

Figure 6. Influence of the liquid physical properties and micro-mixer geometry. Inlet of $200 \mu \mathrm{m}$ and outlet of $1000 \mu \mathrm{m}$. (a) Influence of junction angle mixer $\theta_{\text {mixer }}$. (b) Influence of Surface tension. (c) Influence of viscosity.

The similar tendency is observed for all the geometries in Figures $6 a, 6 b$ and $6 \mathrm{c}$ with the same power law index $\alpha=0.25$. The effect of the mixing section geometry on the bubble length was studied for three types of mixers as shown in Figure 6a: a cross-shaped mixer for which the liquid inlet channel was perpendicular to the outlet channel. The two other two types were the converging mixers, with respective angles of $45^{\circ}$ and $30^{\circ}$ between both liquid inlet channels and the central gas-liquid outlet channel. The width of the channels in these geometries was $200 \mu \mathrm{m}$ for the gas inlet and $1000 \mu \mathrm{m}$ for the liquid inlet. Experiments were carried out for each geometry using different operating conditions. For a given geometry, the increase of the ratio of gas flowrate to liquid flowrate yields the augmentation of the bubble 
length. However, the bubble size increases with the decrease of the angle $\theta$ (Fig. 6c). The effect of the surface tension was investigated by the addition of the SDS surfactant in water in one micro-mixer's geometry $\left(180^{\circ}\right)$. As expected, the bubble length increases with the surface tension (Fig. 6a). Finally the effect of the liquid viscosity was investigated in the $180^{\circ}$ angle micro-mixer with three liquids of the same surface tension (Fig. 6b). Once again, the bubble length increases logically with the liquid viscosity due to the increase of the shear stresses acting on the bubble.

The factor $\beta$ in Eq. 5 seems to be linked to these three parameters. A dimensional analysis was applied to obtain a dimensionless correlation of bubble length under all operating conditions and mixer's geometries investigated in this study. For this purpose, 150 data points were used to determine such a correlation. Table 3 resumes the correlations obtained for each mixer geometry. The dimensionless numbers based on the viscosity and surface tension were introduced using the physical properties $\mu_{\text {ref }}$ and $\sigma_{\text {ref }}$ of water as a reference. The experimental data are quite well described by these correlations with an average relative error below $3 \%$ and a maximum error of less than $13 \%$.

Table 3. Comparison of the micro-mixer geometries correlations

\begin{tabular}{l|l|l|l|}
\hline$\beta=10.3\left(\frac{\sigma}{\sigma_{r e f}}\right)^{\frac{6}{5}}\left(\frac{\mu}{\mu_{r e f}}\right)^{\frac{1}{15}}$ & $\beta=9\left(\frac{\sigma}{\sigma_{r e f}}\right)\left(\frac{\mu}{\mu_{r e f}}\right)^{\frac{1}{10}}$ & $\beta=7.08\left(\frac{\sigma}{\sigma_{r e f}}\right)^{\frac{3}{4}}\left(\frac{\mu}{\mu_{r e f}}\right)^{\frac{1}{8}}$ \\
$\varepsilon=2.64 \%$ error $(\max 10 \%)$ & $\varepsilon=3 \%$ error $(\max 12 \%)$ & $\varepsilon=2.75 \%$ error $(\max 13 \%)$
\end{tabular}


Two conclusions can be then drawn from this Table. Firstly, the influence of the surface tension is more important than that of the viscosity with a higher power index. This is in agreement with the magnitude of various forces gathered previously in Table 2: the shear stress is much smaller than the surface tension. Secondly, the effect of the surface tension increases with the decrease of the angle $\theta$ through a significant increase of the elongation ratio. This is opposed to the tendency of the viscosity effect. In fact, the power index of the surface tension decreases, and that of the viscosity increases with the angle $\theta$. Clearly, the use of both the $\mu$-PIV technique and high speed camera bring some new information into the understanding of the bubble formation at microscale. Figure 7 shows the flow fields of liquid around a forming bubble respectively in a cross flow-focusing (Fig. 7a) and in a convergence $\left(\theta=60^{\circ}\right)$ flow-focusing (Fig. $\left.7 \mathrm{~b}\right)$. The detailed flow field obtained just before the bubble pinch-off is useful to evaluate the shear stress in these mixers for the comparison with the pressure distribution and surface tension. Obviously, the shear rate is higher in the $180^{\circ}$ angle geometry $\left(500 \mathrm{~s}^{-1}\right)$ than in the $60^{\circ}$ geometry $\left(350 \mathrm{~s}^{-1}\right)$. The effect of the shear stress is therefore more important when $\theta$ increases which is in agreement with correlations reported in Table 3.

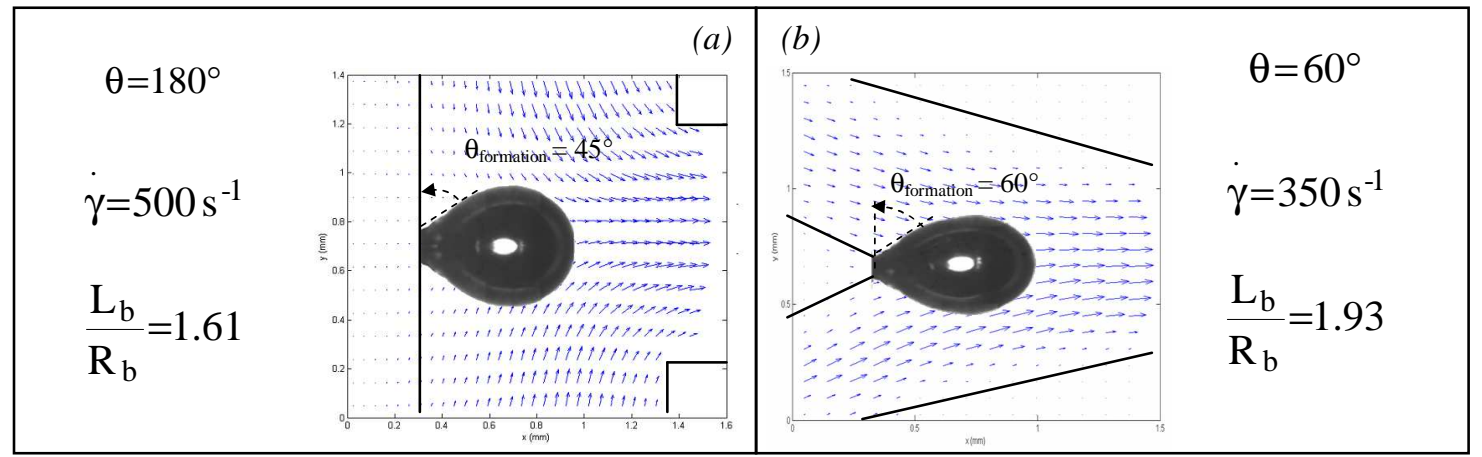

Figure 7. Flow field of a $10^{-9} \mathrm{~m}^{3}$ bubble in two different micro-mixers. 
The angle between the inlet wall and the bubble at its formations ( $\left.\theta_{\text {formation }}\right)$ and the dimensionless ratio of the elongation $\mathrm{L}_{b} / \mathrm{R}_{b}\left(\mathrm{R}_{b}\right.$ is the equivalent radius of the bubble and $\mathrm{L}_{\mathrm{b}}$ the length of the stretched bubble) are also reported in Figure 7 . The bubble is more elongated in the $\mathrm{Y}$-section than in the T-section. A narrower angle such as the $\mathrm{Y}$-section obligates the elongation of a forming bubble so that the effect of the surface tension increases due to the deformation. This confirms the tendency effect of the surface tension proposed in the correlations of Table 3. Thus $\mu$-PIV measurements can provide quantitative information for validating the correlations established for the various mixers. In order to take into account the influence of the mixer angle on the behavior induced by the effect of the liquid viscosity and tension, a $\theta / \theta_{\max }$ was added in correlation of table 3 where $\theta_{\max }$ is the maximal angle (i.e. $180^{\circ}$ ). The following dimensionless correlation was obtained based on about 150 experimental data.

$$
\frac{L}{W}=8,3\left(\frac{\theta_{\max }}{\theta}\right)^{\frac{1}{8}}\left(\frac{\sigma}{\sigma_{\text {ref }}}\right)\left(\frac{\mu}{\mu_{\text {ref }}}\right)^{\frac{1}{10}}\left(\frac{Q_{\text {gas }}}{Q_{\text {liquid }}}\right)^{\frac{1}{4}}
$$

Figure 8 shows the good agreement obtained between experimental L/W values and those estimated from this correlation.

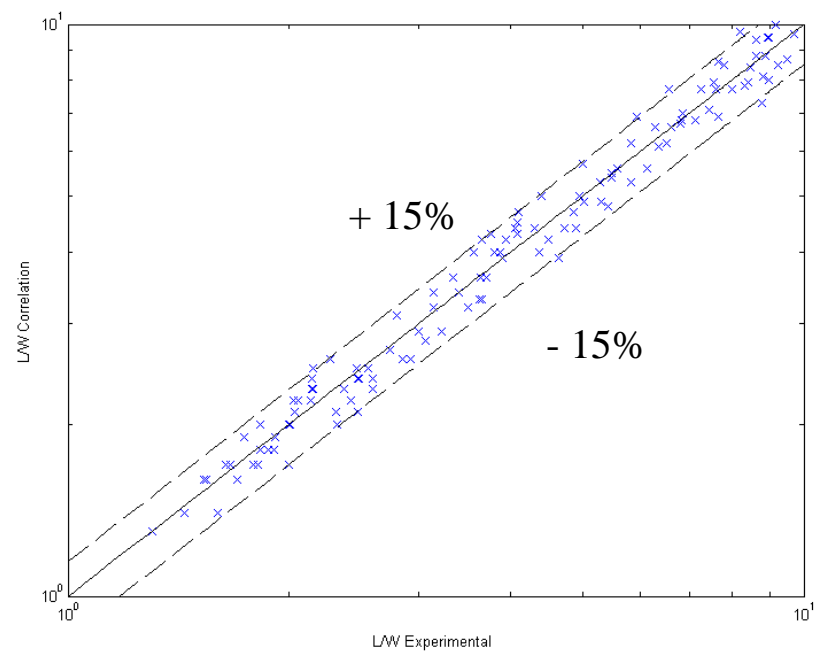

Figure 8. Parity diagram between correlated data and experimental results. 
The average relative error is about $6.5 \%$ with a maximum error of $18.7 \%$. This correlation gives a good estimation for the bubble formation in liquid of viscosity ranging from 1 to 30 mPa.s, surface tension of 40 to $72.5 \mathrm{mN} / \mathrm{m}$, and different geometries and sizes of micromixers (angle of 180,90 and $60^{\circ}$ and $\mathrm{W}=200,500$ and $1000 \mu \mathrm{m}$ ). It could be a useful tool for micro-mixer design taking into account the liquid physical properties as well as the geometry of the micro-mixer. Furthermore, the similar calculation was elaborated for the bubble volume:

$$
\frac{V_{b}}{W^{3}}=300\left(\frac{\theta_{c}}{\theta_{m}}\right)^{\frac{1}{6}}\left(\frac{\mu_{l}}{\mu}\right)^{\frac{1}{50}}\left(\frac{Q_{\text {gas }}}{Q_{\text {liquid }}}\right)^{\frac{1}{4}}
$$

With an average error of about $12 \%$, the parity diagram is not reported here as it is very close to Fig. 8. In this correlation, the surface tension is introduced through the contact angle $\theta_{\text {contact }}$ to simplify the use of the correlation. As shown in Table 2, the effect of shear stress is smaller as compared to the surface tension and pressure distribution, which is in good agreement with this correlation.

\section{Conclusion}

The segmented flow of a train of bubbles finds very wide applications of multiphase flow in microfluidic devices. In this work, experiments were carried out to study the gas-liquid flows in microchannels. The bubble shape, size and formation mechanism were investigated under different flow conditions. The mechanism of bubble formation of in a flow-focusing micromixer was previously proposed as pinched off by the pressure difference in both phases (Garstecki et al., 2006; Cubaud et al., 2005). The current work confirms this general mechanism of bubble formation by the mean of $\mu$-PIV measurements. The liquid flow fields of the continuous phase during the formation of bubbles provide important quantitative details 
that were never reported in literature for this kind of micro-mixer. Moreover, the bubble size was shown dependant on the liquid physical properties such as the viscosity and surface tension as well as the geometries of the mixing section. According to the micro-mixer's geometry, the viscosity and the surface tension have different influence. Finally, some correlations were proposed to predict the bubble volume and length for all gas-liquid systems and micro-mixer geometries investigated. The predicted values are in good agreement with the experimental results.

Acknowledgements: The financial assistance provided by the French Ministère de l'Enseignement Supérieur et de la Recherche is gratefully acknowledged.

\section{Notation}

$V_{b} \quad$ bubble volume, $m^{3}$

W Channel width, $m$

$Q \quad$ Flowrate, $m^{3} s^{-1}$

Length, $m$

$R_{b} \quad$ Bubble radius, $m$

$r \quad$ Radius, $m$

$k \quad$ Boltzmann constant, $J / K$

D Diffusion coefficient, $\mathrm{m}^{2} / \mathrm{s}$

$T \quad$ Temperature, $K$

$v \quad$ Velocity, $\mathrm{m} / \mathrm{s}$ 


\section{Greek Letters}

$\dot{\gamma} \quad$ Shear rate, $s^{-1}$

$\Sigma \quad$ Standard deviation, $m$

$\alpha, \beta \quad$ Power law coefficient

$\mu \quad$ Viscosity of the liquid, Pa.s

$\theta \quad$ Angle, ${ }^{\circ}$

$\rho \quad$ Density, $k g . \mathrm{m}^{-3}$

$\sigma \quad$ Surface tension, N.m $m^{-1}$

Subscripts

$\begin{array}{ll}g & \text { Gas } \\ l & \text { liquid } \\ p & \text { Particle } \\ r \text { ref } & \text { Reference properties } \\ & \\ \text { max } & \text { Maximal }\end{array}$




\section{Literature Cited}

1. Wu, J., Lu, Z.Y., Hu, J.C., Feng, L., Huang, J.D., Gu, X.S. Water Science and Technology. 2006, 54, 9-16.

2. Frank, X., Dietrich, N., Wu, J., Barraud, R., Li, H.Z. Chemical Engineering Science. 2007, 62, 7090-7097.

3. Garstecki, P., Fuerstman, M.J., Stone, H.A., Whitesides. G.M. Lab on chip. 2006, 6, 437-446.

4. Chambers, R.D., Holling, D., Spink, R.C.H., Sandford, G. Lab on Chip. 2001, 1, 132137.

5. Kobayashi, J., Mori, Y., Okamoto, K., Akiyama, R., Ueno, M., Kitamori, T., Kobayashi, S. Science. 2004, 304, 1305-1308.

6. Burns, M.A., Johnson, B.N., Brahmasandra, S.N., JamesK.H., Webster, R., Krishnan, M., Sammarco, T.S, Man, P.M., Jones, D., Heldsinger, D., Mastrangelo, C.H., and Burke, D.T. Science. 1998, 282, 484-487.

7. $\mathrm{Qu}, \mathrm{W} ., \mathrm{Mudawar}, \mathrm{I}$. International Journal of Heat and Mass Transfer. 2002, 45, 2549-2565.

8. Yen, B.K.H., Gunther, A., Schmidt, M.A., Jensen, K.F. Angewandte Chemie International. 2005, 44, 5447-5451.

9. Zhang, H., Tumarkin, E., Peerani, R., Nie, Z., Sullan, R. M. A., Walker, G.C., Kumacheva, E. Journal of the American Chemical Society. 2006, 128, 12205-12210.

10. Dittrich, P.S., Manz, A. Nature Reviews Drug Discovery. 2006, 5, 210-218.

11. Waelchli, S., von Rohr, R. International Journal of Multiphase Flow. 2006, 32, 791806.

12. Cubaud, T., Ho, C.-M. Physics of Fluids. 2004, 16, 4575-4585.

13. Haverkamp, V., Hessel, V., Lowe, H., Menges, G., Warnier, M. J. F., Rebrov, E. V., de Croon, M. H. J. M., Schouten, J. C., Liauw, M. A. Chemical Engineering Technology. 2006, 29, 1015-1026.

14. van der Graaf, S., Nisisako, T., Schroe, C.G.P.H., van der Sman, R.G.M., Boom, R. M. Langmuir. 2006, 22, 4144-4152.

15. Guillot, P., Colin, A. Physical Review E. 2005, 72, 066301.

16. Nisisako, T., Torii, T., Higuchi, T. Lab on a Chip. 2002, 2, 24-26.

17. Thorsen, T., Roberts, W. R., Arnold, F. H., Quake, S. R. Physical Review Letters. 2001, 86, 4163-4166.

18. Tice, J. D., Song, H., Lyon, A. D., Ismagilov, R. F. Langmuir. 2003, 19, 9127-9133.

19. Xu, J.H., Li, S.W., Wang, Y.J., Luo, G.S. Applied Physics Letters. 2006, 88, 133506.

20. Anna, S.L., Bontoux, N., and Stone, H.A. Applied Physics Letters. 2003, 82, 364-366.

21. Cubaud, T., Tatineni, M., Zhong, X. and Ho, C.-M. Physical Review E. 2005, 27, 037302 .

22. Ganan-Calvo, A.M., Gordillo. J.M. Physical Review Letters. 2001, 87, 274501.

23. Garstecki, P., Stone, H.A., Whitesides, G.M. Phys. Rev. Lett. 2005, 94, 164501.

24. Cubaud, T., Ho, C.-M. Physics of Fluids. 2004, 16, 4575-4585.

25. Lindken, R., Westerweel, J., Wieneke, B. Experiments in Fluids. 2006, 11, 161-171.

26. Thulasidas, T.C., Abraham, M.A., Cerro, R.L. Chemical Engineering Science. 1997, 52, 2947-2962.

27. Xiong, R., Bai, M., Chung, J.N. Journal of Micromechanics and Microengineering, 2007, 17, 1002-1011.

28. Fries, D.M., Waelchli, S., Rudolf von Rohr, P. Chemical Engineering Journal. 2007, $135, \mathrm{~S} 37-45$. 
29. van Steijn, V., Kreutzer, M.T., Kleijn C.R. Chemical Engineering Science. 2007, 62, $7505-7514$.

30. Dietrich, N., Poncin, S., Li H.Z. Récents Progrès en Génie des Procédés, 95, Ed. SFGP, Paris, France, 2007.

31. Gañán-Calvo, A.M. Physical Review Letters. 1998, 80, 285-288.

32. Fan, L.S., Yu, Z., Hemminger, O. Chemical Engineering Science. 2007, 62, 75057514.

33. Brown, R.. Edinburgh New Phil. J., 1928

34. Einstein, A. Ann. d. Physik. 1905, 17, 549-560 (also demonstrated by Sutherland, W.. Phil. Mag. 1905, 9, 781). 


\section{Caption of tables}

Table 1. Properties of the different liquids used in this study

Table 2. Competition occurring between the different pressure drop at the formation of a bubble in a flow-focusing micro-mixer. For a bubble radius of $r=100 \mu \mathrm{m}$.

Table 3. Comparison of the three micro-mixers geometries

\section{Caption of figures}

Figure 1. Illustration of the micro fluidic chip used to generate micro-bubble. From the left to the right, cross shape $\left(180^{\circ}\right)$, Convergence shape $\left(90^{\circ}\right.$ and $\left.60^{\circ}\right)$.

Figure 2. Micro-Particle Image Velocimetry principle ( $\mu$-PIV).

Figure 3. Bubble formation in cross flow-focusing micro-mixer. $\mathrm{V}_{\mathrm{b}}=10^{-9} \mathrm{~m}^{3}$.

Figure 4. Velocity field measure by $\mu$-PIV at a 10-9 m3 bubble formation in a cross flowfocusing mixers. The height of the $\mu$-PIV measurement plane is situated in the middle of the channel.

Figure 5. (a) Influence of gas or liquid flowrate on the bubble length of the bubble divided by the channels width (L/W). ( $\times$ ) $\mathrm{Q}_{\mathrm{g}}$ varies and $\mathrm{Q}_{1}$ is constant. $(\triangle) \mathrm{Q}_{1}$ varies and $\mathrm{Q}_{\mathrm{g}}$ is constant .Inlet channel size is $200 \mu \mathrm{m}$ and outlet channel size is $1000 \mu \mathrm{m}$.(b) Influence of inlet and outlet channels size on the evolution of $\mathrm{L} / \mathrm{W}$ in function of the flowrates ratios in water.

Figure 6. Influence of physical properties of liquid and micro-mixing geometries. Inlet of $200 \mu \mathrm{m}$ and outlet of $1000 \mu \mathrm{m}$. (a) Influence of angle mixer $\theta_{\text {mixer }}$ (b) Influence of Surface tension. (c) Influence of viscosity.

Figure 7. Velocity flow field of a $10^{-9} \mathrm{~m}^{3}$ bubble in two different micro-mixer.

Figure 8. Parity diagram between the correlation data and the experimental results. 
Graphical Abstract - TOC

\section{BUBBLE FORMATION IN FLOW-FOCUSING MICROREACTORS:}
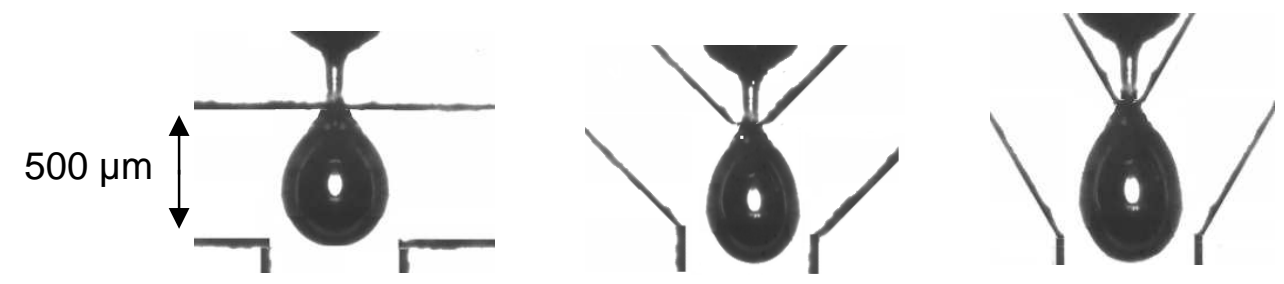

$\mu$-Particle Image Velocimetry measurements ( $\mu$-PIV)
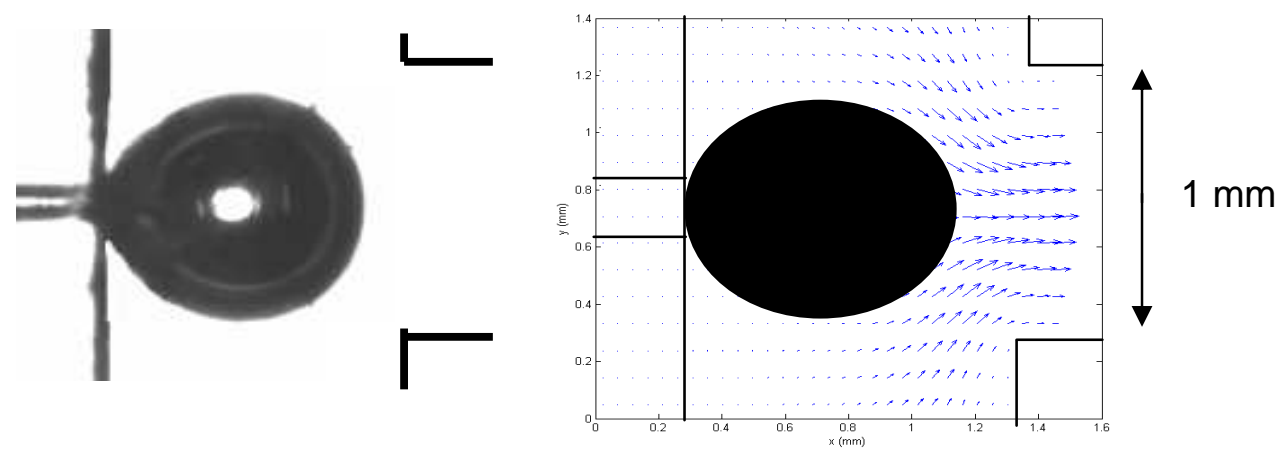